\title{
On Linsu Kim's Imitation to Innovation: The Dynamics of Korea's Technological Learning
}

(Boston: Harvard Business School Press, 1997)

\author{
Hyungsub Choi
}

Received: 16 July 2007 / Accepted: 16 July 2007 /

Published online: 30 January 2008

(C) National Science Council, Taiwan 2008

How does a nation transform itself from an imitative one to an innovative one? This is a challenge that most catching-up countries face as they make their way up the ladder in the world economy. In the twentieth century, however, examples of countries that successfully made the transition are rare, South Korea being one of the very few. In this book, the late Linsu Kim analyzes Korea's experience of rapid industrialization (1960-1995) and identifies the late 1970s and early 1980s as the critical turning point at which the Korean nation made the transition from "imitation to innovation."

If you are in search of a clear-cut answer as to how the Koreans managed to make that transition, this is not the book for you. Kim enumerates a long list of "factors""government, chaebols, education, export policy, technology transfer strategy, research, development policy, sociocultural systems, and private-sector strategy" (p. 194) - that interact with one another to create a complex dynamics of change. The author's intention is to provide a comprehensive overview of how this dynamics of change played out in three key industries (automobiles, consumer electronics, and semiconductors), with an additional chapter on small and medium-sized enterprises.

Korea's technological trajectory, as Kim observes, has been in the reverse direction compared to that of advanced countries. Scholars in technology studies have long debated whether technology determines human action. If the tenet of technological determinism holds anywhere, it is at the catching-up countries constrained by the technological trajectories set by advanced nations. As particular technologies go through stages of development in advanced countries-emergence, consolidation, and maturity-developing nations typically take the opposite route, beginning with mature technologies and gradually moving onto emerging ones. (Figure 4-2, p. 89). If this strategy is successful, the catching-up country acquires the capability to conduct indigenous development and research activities.

\footnotetext{
H. Choi $(\bowtie)$

Center for Contemporary History and Policy, Chemical Heritage Foundation,

315 Chestnut, Philadelphia, PA 19106-2702, USA

e-mail: hchoi@chemheritage.org
} 
No analysis of a developing country's technological capability would be complete without a comment on the role of the government. Indeed, the Korean government employed an array of policy measures to facilitate the firms' technological learning, including promotion of chaebols through subsidies and incentives, export policy, and technology transfer policy. These measures, according to Kim, were carefully designed to move the nation's technological capability along the stages from technology importation to indigenous R\&D. Government intervention does not account for the whole story, however: as Kim makes it clear, "[t]he government... provided a policy environment, but it was industry that made it reality" (p. 21).

The private industry began to eclipse the government circa 1980. If the government-funded research institutes were at the forefront of advanced technology during the 1960s and 1970s, industrial R\&D took over the role in subsequent decades. This was a prolonged process of technological learning. Beginning with acquiring foreign technology through patent licensing and importing capital goods, firms gradually learned to substitute foreign parts with domestically manufactured ones, then eventually attained the capability to design the entire system. In order to accelerate the process, industry leaders periodically constructed "crises" that drove the workers to meet unrealistic deadlines. The government, for its part, provided the background-extension of loans, protection against foreign competition, and suppression of labor-against which the industry could set such audacious goals.

Kim's interest is in explaining how Korea made the transition from imitation to innovation (which he accomplishes in rather broad strokes), but not why it happened. There are some clues, however. His case studies indicate that the urge to acquire indigenous technological capability arose from very concrete needs, especially when foreign firms began to refuse sharing their technologies. For example, Mitsubishi, which provided the core technology to Hyundai Motors, suddenly refused to renew the contract in the mid-1980s when the Korean automakers successfully penetrated the North American market with its Excel model (p. 119). Similarly, LG Electronics found that "no foreign color TV maker was willing to license to Korean makers to help them invade the U.S. market" in the mid-1970s (p. 136). It was only when these external crises occurred that Korean firms began to consider investing seriously in indigenous R\&D.

On the other hand, it is worth noting that there is no clear-cut line between the imitative and innovative stages. In fact, one of the purposes of conducting indigenous $\mathrm{R} \& \mathrm{D}$ was to gain a stronger bargaining position in acquiring foreign patent licenses, and acquiring foreign technology allowed catching-up firms to build up internal technological capabilities. In other words, imitation leads to innovation and vice versa.

Kim's findings are less than surprising. The three industries at the core of his analysis largely fall within the parameters of his theoretical construct. Perhaps future students of Korean technology will benefit from pursuing more specificity. Rather than trying to generalize, one should try to understand the inner workings of the complex dynamics from the bottom up. Who were the individuals behind the decision to invest in indigenous R\&D at Samsung in the mid-1970s? Did they truly believe that building up internal technological capabilities will help them acquire foreign patents? Was there resistance to this strategy? And if so, how did they overcome it, and what was the logic they employed to do so? Did this logic reflect 
the broader sense of Korea's place in the global technological pecking order? These are no doubt difficult questions to answer, but they are critical to gaining a better understanding of the transition from imitation to innovation.

For those who wish to take on these challenges, this book provides a useful heuristic and a starting point. It would be of interest to a broad range of historians and social scientists aiming to take a closer look at the innovative process in contemporary South Korea. As a pioneering study of Korean technology, Imitation to Innovation will stay on the reading list for future students for years to come. 